\title{
Interdisciplinary analysis of the influence of monolingualism and bilingualism on personality traits
}

\author{
Valentina Kurilkina*, Ekaterina Vinokurova, Natalia Yeliseyeva, and Sergey Khachirov \\ North-Eastern Federal University, 58 Belinsky str. Yakutsk, 677000, Republic of Sakha (Yakutia), Russia
}

\begin{abstract}
In the age of globalization, computerization, digitalization, the problem of the presence of such qualities as soft skills, which include emotional intelligence, communication skills, the ability to solve problems, the ability to make decisions, the ability to work in a team, independence, introspection, selforganization, reflection and other qualities, is becoming urgent. These qualities should ensure the competitiveness of a young specialist in a constantly changing increasingly complex world in the age of widespread digital technologies, artificial intelligence, robotics, the Internet of things, etc. The article analyzes the results of a study carried out among students of primary school age and student age. It was necessary to find out what advantages the knowledge of two languages (native and non-native) gives students in the development of cognitive abilities and personality traits. To this end, an interdisciplinary analysis of the influence of bilingualism on the development of cognitive processes and personal qualities of two age categories was carried out. The analysis of the research results shows that bilingualism gives certain advantages in the development of the abilities of students of primary school and student age to adapt, communicative qualities, in the ability to pose and solve problems, in the ability to defend their beliefs and interests.
\end{abstract}

\section{Introduction}

Among the characteristics of modern society is the diversity and interpenetration of cultural traditions and linguistic diversity. This can give rise to a number of problems, such as the threat of extinction and loss of traditional cultures and languages. This is especially true for small peoples and nationalities. In Siberia and the Far East of Russia, in particular, in such regions as Kalmykia, Altai Territory, Buryatia, many languages of the Turkic-Mongolian peoples are under threat of extinction. In the Republic of Sakha (Yakutia), a significant number of young and middle-aged people cannot communicate in their native language, although this problem is considered less urgent and acute. This can lead to the problem of the disappearance of the native language of the peoples of Siberia and the Far East, especially among the younger generation. The loss of national languages leads to the disappearance of original peoples and cultures, the impoverishment of the cultural and linguistic wealth and diversity of all mankind. The language of a nation is given to a person from birth and bears the imprint of the culture, spirituality and traditions of his people. Through their mother tongue, a person feels belonging to their community and can participate in culture and traditions. With the help of language, a person thinks, builds his picture of the world, activates his consciousness [1,2].

Knowledge of the native language is the basis for the development of a person's personality. Nowadays, during the period of active changes caused by digitalization, globalization, computerization, in the age of enormous competition, the significance and role of personal qualities for self-realization are being revised. Personal qualities, which until recently occupied a certain weight and significance for professional growth and personal self-development, are beginning to change their place in the structure of professionally important qualities. According to the World Economic Forum in 2020, the top 10 soft skills are [3]:

- Persuasion and negotiation;

- Emotional intelligence;

- $\quad$ Resilience, stress tolerance and flexibility;

- Technology use, monitoring and control;

- $\quad$ Leadership and social influence;

- Creativity, originality and initiative;

- Critical thinking and analysis;

- Complex problem-solving;

- Active learning strategies;

- Analytical thinking and innovations.

\section{Materials and methods}

Currently, many researchers believe that bilingualism has a positive effect on the development of cognitive processes and the success of children [4,5].

Some researchers do not find significant differences between bilinguals and monolinguals [6].

First, let us explain our basic terms. Bilingualism (bilingualism) is defined as "the coexistence, functioning and interaction of two languages within the same

\footnotetext{
Corresponding author: kuril_vn@mail.ru
} 
linguistic/speech community, whose members use these languages in social and communicative spheres, depending on the parameters of the speech act and in accordance with collective norms and values" [7]. We understand bilingualism as a state of a community in which two languages can be used in the same interaction, and bilingual people are fluent in two languages at the same time (native and non-native), using them in everyday practice. Monolingualism is a command of one language from the very beginning of the development of speech. In the realities of the Republic of Sakha (Yakutia), bilingualism means knowledge of the native and Russian languages, and monolinguism means knowledge of the Russian language. In this article, by personality traits, we mean personality traits, as well as cognitive and creative abilities.

In our study, we are interested in the influence of knowledge and non-knowledge of the native language (bilingual and monolingual) on the personality traits of primary schoolchildren and students.

As a subject of research, we studied personal characteristics, as well as cognitive and creative abilities.

The object is, respectively, children of primary school age and youth of student age. The choice of the object and subject of research is due to the fact that it is these age periods, in our opinion, that are distinguished by active knowledge of the world-children master educational activities, a new social situation appears, and they take on a new social role in primary school age. The transition to the role of a student also presupposes a new role and a new social situation. Overall, these changes are a powerful catalyst for cognition and personality development.

A feature of our research is interdisciplinary analysis. The results obtained are analyzed from the point of view of psychological and pedagogical patterns of personality development. The choice of pedagogy, to be more specific, ethnopedagogy, is due to the fact that in ethnopedagogy, great importance is attached to the mastery of the native language as a transmitter of cultural traditions from parent to child. G.N. Volkov considered the mother's language to be the basis that develops the personality. If the mother did not pass on her native language to the child, then she spiritually broke the connection with him, which in the future generates a complex of human and ethical inferiority. Outside the sphere of spiritual, national culture, there can be no full-fledged education [8].

The study was carried out in two directions: the first direction of the study is aimed at studying the relationship between native language proficiency and the development of cognitive processes (the influence of the native language on the development of cognitive processes). The research was carried out in two stages. The first stage included the formation of a homogeneous experimental group according to the level of proficiency in two languages among schoolchildren in grades 1 and 2. At the second stage, the study was carried out in the experimental (bilingual) and control (monolingual) groups. Here, the methodological toolkit included the following projective drawing methods due to the age characteristics of the respondents: "Verbal fantasy (speech imagination)", "Drawing", "Definition of concepts, clarification of reasons, identification of similarities and differences in objects" [9]. The results obtained were statistically processed using factor analysis.

The second direction of the study is aimed at identifying the knowledge of the native language on the personal qualities of monolingual and bilingual students. As a research method, the Cattell method (form A) [10] was defined with subsequent processing according to the Mann-Whitney criterion and factor analysis.

The choice of statistical methods for data processing was dictated, in addition to the grading scale, the sample size and the normal distribution.

The sample of research in the first direction consists of students in grades 1 and 2, 100 children in total. Of these, 22 are bilinguals who speak Yakut (native) and Russian, 78 are monolinguals who speak only Russian. In the second direction, the sample consists of students aged 18-22 years. In total, the sample includes 153 people, including 122 bilingual students and 31 monolinguals.

In terms of age, gender, socioeconomic status, there were no significant differences between the respondents in both areas of the study.

\section{Results}

Results of the first study. In the first direction, the following results were obtained.

Table 1 presents the results of factor analysis for two compared groups: $\mathrm{n}$ the group of schoolchildren who speak two languages and in the group of schoolchildren who speak one language. In the bilingual group, 6 factors were identified (total variance was $78.99 \%$ ).

The first factor, conventionally called "imagination", includes the following components: the depth of the characters' elaboration of the verbal and non-verbal subtests, the emotionality of the images and the speed of inventing the story. We assume that this group includes children with good dynamic characteristics of cognitive processes, who also have a sufficient level of emotional intelligence.

The second factor, the conventional name of which is "non-verbal imagination", includes the following components: the richness of non-verbal images and the impressionability of non-verbal images, as well as the speed of coming up with a story. A feature of the children of this group is the development of a concretefigurative imagination. Here, the non-verbal side of cognitive abilities is developed more than verbal qualities.

The third factor can be defined as "verbal originality". This includes the following components: verbal singularity and verbal wealth. Unlike the previous factor, the verbal side of creative and cognitive abilities is revealed here.

We called the fourth factor "realism". This factor includes the following components: richness of drawing images, elaboration and detailing of images presented in the story; unusual drawing with a negative pole. This 
factor is represented by an orientation towards the aesthetic side of the imagination, the desire of schoolchildren to maximize the reliability of the transfer of images.

We called the fifth factor "schematic". It combines two components: the speed of imagining the image and the negative value of the wealth of images. Of course, with the rapid generation of characters in the story, the elaboration and detailing of the images suffers.

The sixth factor also has two components: general awareness and emotionality of verbal images. We will call this factor "realism". The name of this factor is due to the fact that here children show a level of awareness of themselves and the world around them. Knowledge is reflected in the emotional images of the characters.

Table 1. Results of factor analysis of cognitive and creative abilities of children of primary school

\begin{tabular}{|c|c|c|c|c|c|c|c|c|c|c|}
\hline \multirow[t]{2}{*}{ Variables } & \multicolumn{6}{|c|}{ Bilingual } & \multicolumn{4}{|c|}{ Monolingual } \\
\hline & 1 & 2 & 3 & 4 & 5 & 6 & 1 & 2 & 3 & 4 \\
\hline Depth (non-verbal) & 0.876 & & & & & & & & & 0.785 \\
\hline Depth (verbal) & 0.484 & & & 0.564 & & & & & & 0.417 \\
\hline $\begin{array}{l}\text { Impressiveness } \\
\text { (verbal) }\end{array}$ & 0.528 & & & & & 0.491 & & & 0.775 & \\
\hline Awareness & & & & & & 0.879 & -0.614 & & & 0.524 \\
\hline Speed (verbal) & & & & & 0.925 & & 0.788 & & & \\
\hline Unusualness (verbal) & & & 0.879 & & & & & & 0.766 & \\
\hline Wealth (verbal) & & & 0.707 & & -0.449 & & & & & 0.494 \\
\hline Speed (non-verbal) & 0.428 & 0.592 & & & & & & 0.759 & & \\
\hline $\begin{array}{l}\text { Unusualness (non- } \\
\text { verbal) }\end{array}$ & & & & & & & 0.683 & & & \\
\hline Wealth (non-verbal) & & 0.704 & & 0.527 & & & & 0.784 & & \\
\hline \multirow[t]{2}{*}{$\begin{array}{l}\text { Impressiveness (non- } \\
\text { verbal) }\end{array}$} & & 0.797 & & & & & & & & \\
\hline & \multicolumn{6}{|c|}{$\begin{array}{l}\text { Isolation method: Principal component analysis. } \\
\text { Rotation method: Varimax with Kaiser } \\
\text { normalization. } \\
\text { a. Rotation converged in } 8 \text { iterations. }\end{array}$} & \multicolumn{4}{|c|}{$\begin{array}{l}\text { Isolation method: Principal component } \\
\text { analysis. } \\
\text { Rotation method: Varimax with Kaiser } \\
\text { normalization. } \\
\text { a. Rotation converged in } 9 \text { iterations }\end{array}$} \\
\hline
\end{tabular}

In the group of monolingual schoolchildren who do not speak their native language, 5 factors were identified (total variance $68.83 \%$ ). Let us consider each factor separately.

The first factor we will call "superficiality." The factor combines the following components: non-verbal originality, the speed of coming up with an image and, with a negative value, the components of awareness. In this case, the speed and unusualness of the drawings is manifested to the detriment of the child's awareness of himself and the world around him.

The second factor is "the speed of non-verbal imagery". The factor consists of two components: speed and richness of pictorial images. Probably, this group included schoolchildren with pronounced artistic abilities. At the same time, verbal abilities are not manifested in this factor.

The third factor will be called "the unusualness of verbal images". This factor includes the following components: verbal unusualness and verbal impressionability. A feature of the answers included in this factor is the originality and unusualness of the characters in the stories and the impressionability, emotionality of the images.

The fourth factor is general awareness, richness and depth of story and drawing. This factor will be called "the completeness of verbal and non-verbal images". In our opinion, this group is represented by schoolchildren with a broad outlook, developed imagination and, possibly, creative thinking.

In the second direction of research, the following results were obtained. According to the Mann-Whitney criterion, statistically significant differences were identified according to the following features: isolation $(p \leq 0.018)$, restraint $(p \leq 0.012)$, normative behavior $(\mathrm{p} \leq 0.0)$, self-control $(\mathrm{p} \leq 0.0043)$, anxiety $(\mathrm{p} \leq 0.027)$, conformism $(\mathrm{p} \leq 0.001)$. Descriptive statistics for these factors are presented in Table 2. 
Table 2. Descriptive statistics of students' personal qualities.

\begin{tabular}{|c|c|c|c|c|c|c|c|c|}
\hline \multirow[t]{2}{*}{ Factor } & \multirow[t]{2}{*}{$\begin{array}{l}\text { Gro } \\
\text { up* }\end{array}$} & \multirow[t]{2}{*}{ Average } & \multirow{2}{*}{$\begin{array}{l}\text { Average } \\
\text { sq. } \\
\text { deviation }\end{array}$} & \multirow[t]{2}{*}{$\begin{array}{l}\text { Standard } \\
\text { error }\end{array}$} & \multicolumn{2}{|c|}{$\begin{array}{l}95 \% \text { confidence } \\
\text { interval for the mean }\end{array}$} & \multirow[t]{2}{*}{$\begin{array}{l}\text { Minim } \\
\text { um }\end{array}$} & \multirow[t]{2}{*}{$\begin{array}{l}\text { Maxi } \\
\text { mum }\end{array}$} \\
\hline & & & & & $\begin{array}{l}\text { Lower } \\
\text { limit }\end{array}$ & $\begin{array}{l}\text { Upper } \\
\text { limit }\end{array}$ & & \\
\hline \multirow{2}{*}{$\begin{array}{l}\text { Closure- } \\
\text { sociability }\end{array}$} & 1 & 6.5806 & 1.72770 & 0.31030 & 5.9469 & 7.2144 & 3.00 & 10.00 \\
\hline & 2 & 5.4516 & 1.84099 & 0.33065 & 4.7763 & 6.1269 & 1.00 & 9.00 \\
\hline \multirow{2}{*}{$\begin{array}{l}\text { Restraint- } \\
\text { expressiveness }\end{array}$} & 1 & 5.9355 & 1.82456 & 0.32770 & 5.2662 & 6.6047 & 2.00 & 10.00 \\
\hline & 2 & 4.6129 & 2.27563 & 0.40872 & 3.7782 & 5.4476 & 2.00 & 10.00 \\
\hline \multirow{2}{*}{$\begin{array}{l}\text { Normative } \\
\text { behavior }\end{array}$} & 1 & 6.2581 & 1.45986 & 0.26220 & 5.7226 & 6.7935 & 3.00 & 9.00 \\
\hline & 2 & 4.6452 & 1.81748 & 0.32643 & 3.9785 & 5.3118 & 1.00 & 9.00 \\
\hline \multirow[t]{2}{*}{ Self-control } & 1 & 6.7742 & 2.26141 & 0.40616 & 5.9447 & 7.6037 & 2.00 & 10.00 \\
\hline & 2 & 5.7742 & 1.78344 & 0.32031 & 5.1200 & 6.4284 & 2.00 & 10.00 \\
\hline \multirow[t]{2}{*}{ Conformism } & 1 & 4.7548 & 1.97937 & 0.35550 & 4.0288 & 5.4809 & 1.60 & 9.30 \\
\hline & 2 & 6.1172 & 1.64882 & 0.30618 & 5.4901 & 6.7444 & 3.60 & 9.30 \\
\hline \multirow[t]{2}{*}{ Anxiety } & 1 & 31 & 5.1935 & 1.94815 & 0.34990 & 4.4790 & 5.9081 & 1.00 \\
\hline & 2 & 29 & 6.5207 & 3.19121 & 0.59259 & 5.3068 & 7.7346 & -3.00 \\
\hline
\end{tabular}

* where group 1 are bilingual students, group 2 are monolingual students

The first factor, according to Cattell factor $\mathrm{A}$, is defined as "isolation - sociability". In our study, this factor revealed a statistically significant difference between young people who speak their native Yakut language and those who do not $(\mathrm{p} \leq 0.018)$. Evidently from Table 2, the average value in the group of people who know their native language (6.5) is higher than among people who do not speak their native language (5.4). Thus, persons who do not speak their native language may have difficulties in establishing interpersonal direct contacts. For these people, it is preferable to work alone, develop ideas, etc. It is worth noting that according to the classical interpretation of the Cattell scales, despite the fact that the average indicators of persons who speak their native language are higher than those in the other group; the values do not reach the indicated 7 points. This fact may indicate a certain restraint in communication.

The next statistically significant difference was found on the "restraint - expressiveness" scale $(\mathrm{p} \leq 0.012)$. Here, the average value is also higher for those who speak their native language (5.9) compared to those who do not speak their native language (4.6). On this scale, the average values also do not exceed up to the $\mathrm{F}+$ sign. Thus, we can talk about relative differences within a certain range. Persons who do not speak their native language more strongly express caution, prudence in choosing a communication partner, a tendency to concern, anxiety about the future, pessimism in the perception of reality, restraint in the manifestation of emotions.

A statistically significant difference was also revealed on the scale "level of normative behavior" $(\mathrm{p} \leq 0.0)$. This scale characterizes the features of the emotional-volitional sphere (persistence, organization vs. irresponsibility, disorganization) and the features of the regulation of social behavior (acceptance or disregard of generally accepted moral rules and norms). There is a lack of agreement with generally accepted moral rules and standards, flexible in relation to social norms. The average value in the group of monolinguals is 4.6; in the group having the proficiency of the native language, the average value is 6.3. In our opinion, here it is more about a tendency to look for a favorable moment for oneself, a desire to avoid rules and responsibility than to a tendency to inconstancy, susceptibility to the influence of feelings, chance and circumstances. In the group of people who speak their native language, persistence, reliability, and commitment are observed.

The scale "level of self-control" characterizes a person's ability to internal organization and control. For 
this school, the Mann-Whitney $\mathrm{U}$ test revealed a statically significant difference $(p \leq 0.0043)$. In the group of people who speak their own language, the level of self-control is higher (6.7) than among people who do not know their native language (5.7). It should be noted that, according to this scale, in general, both groups have rather high indicators. Therefore, we can talk about different levels of the severity of purposefulness, the ability to control their emotions and behavior, the presence of principles, beliefs.

The differences are also highlighted in the secondary factors allocated by Cattell. A significant difference in the level of anxiety by the measured criterion $(p \leq 0.027)$ is highlighted. Persons who do not speak their native language are more satisfied with what they have than those who know their native language.

There are also statistically significant differences in the level of conformity $(\mathrm{p} \leq 0.001)$. Individuals who speak their native language are slightly more independent and proactive (6.1) than those who do not speak their native language (5.4).

\section{Discussion}

The experimental data obtained above can possibly be explained on the basis of the pedagogical and psychological foundations of the structure of the human psyche.

At primary school age, the foundation of knowledge about the world around begins to be laid, thinking is formed and developed, and basic transformations in the cognitive sphere take place. At this stage, the formation of mental and mental development takes place. In the concept of J. Piaget, the stages of a child's development are highlighted: the sensorimotor period (from 0 to 2 years); preoperative period (from 2 to 7 years); the period of specific operations ( 7 to 11 years); postoperative period (11 to 15 years). Schoolchildren of 8-9 years old are in the stage of specific operations. This stage is characterized by the fact that the intellectual abilities of children reach a new level. At this age, visual-figurative and logical thinking begins to form. Visual-figurative thinking in children of primary school age is the basis for the formation and development of logical thinking. At the age of 8-9 years, schoolchildren can use visualeffective, visual-figurative and abstract-logical thinking. At this age, the formation in children of the ability to generalize and establish cause-and-effect relationships begins. The success of educational activity depends on the characteristics of the development of cognitive processes.

Let us consider the results of a study in bilingual schoolchildren.

Bilingual schoolchildren have a rich imagination and developed speech. Imagination is closely related to such cognitive processes as perception, attention, memory, thinking, speech. With the help of imagination, the child transforms information into something new. The transition from visual-figurative thinking to logical and abstract thinking occurs through imagination. This means that for bilingual children, the process of transition from visual-figurative thinking to logical thinking when creating the appropriate conditions should not cause certain difficulties, and they can be successful in the future in educational activities.

The sixth factor for bilinguals, "realism", includes general awareness and emotionality of verbal images. General awareness is an essential component of a child's cognitive ability. Awareness means the ability of a person, on the basis of his knowledge and information, to express an attitude towards an object, to be aware of feelings and emotions. Bilingual children have a well-developed awareness of feelings and emotions and the ability to show an attitude towards the subject.

The first factor, "superficiality" in monolingual children who do not speak their native language, includes the speed of imagining an image, non-verbal originality and negative awareness. This shows that monolingual children can be inattentive to detail. Attention is the main cognitive process that guides a child's activities.

The second factor, "the speed of non-verbal imagery" (monolinguals), shows that monolingual children can be creative.

The level of development of cognitive processes in bilingual children is generally higher than in monolingual children; this shows that bilingual children learn educational material faster and more firmly, they have better developed attention and logical memory, while monolinguals may experience certain difficulties in the cognitive sphere. But monolingual children may have well-developed creative abilities.

If, however, the results obtained are analyzed from the point of view of depth psychology. Then, based on the ideas of K.G. Jung about the structure of the human subconscious, it can be assumed that ignorance of the native language can cause separation from the national archetypes of one's ethnic group. K. Jung believed that the subconscious has a complex structure and consists of 10 layers. World archetypes are located on the deepest layers, racial are on the middle layers, national archetypes are located on the uppermost, closest layers. National archetypes are subconscious programs that accumulate the experience of survival of many generations of ancestors that is left for posterity. K.G. Jung considered it important to decipher these subconscious archetypes for the harmonious life of future generations. The brain is born with a certain structure and evolved over millions of years [11].

Hence, our results may be a manifestation of the fact that: if a child does not speak his native language, then he does not understand his subconscious national archetypes. His psyche is in an imbalance, which is represented by the results of factor analysis of experimental data of primary school children.

Also, our research revealed a certain lack of knowledge of the world around children of primary school age who do not speak their native language. A person learns the world using different sides of the 
organized hierarchy of various modes of human existence - empirical, sociocultural, existential. The growing individual builds his understanding of the phenomena of the surrounding world, events, facts on unequal psychological foundations. The intuitive component of consciousness also plays an active role in cognition. The logical method of cognition is not always actively used, it is also complemented by unconscious ones, rooted in the motivational-demandbased sphere of goal formation and generation of meaning. The paradigm way of understanding is inextricably linked with the cognitive unconscious. In cognitive psychology, understanding a fact, event or phenomenon means that a growing person must build a working model of the phenomenon using different methods of cognition. Morality is built and has meaning for every member of society, but it does not have a personal meaning divorced from interpersonal communication. And the understanding of objects, objects, phenomena is based on generally available, true and the same knowledge for all. For example, morality matters to every member of society, but has no personal meaning. If a child of primary school age does not speak his native language and is cut off from his native national culture, it will be difficult for the child to build a paradigm of knowledge of the world around him. It will also be difficult for him to assimilate the moral foundations of society, if he does not have a transmission link in the form of his native language [12].

Let us consider the results of a study of older young people-students. At this age, from 18-22 years old, they enter the period of late adolescence, which is mainly characterized by the development of personal qualities and the formation of a worldview.

Let us consider the factors underlying the results of this study:

- "restraint vs. expressiveness";

- "low vs. high normality of behavior";

- "high vs. low self-control";

- "conformism vs. nonconformism";

- "isolation vs. sociability";

- "calmness vs. anxiety."

For all these factors, bilingual students have higher rates (Table 2).

A high degree of expressiveness of monolingual students impedes the self-organization of educational activities, on the other hand, restraint, caution of bilinguals can prevent the possibility of rash actions, contribute to better self-organization and management of their behavior and educational and cognitive activities, including the organization of independent work.

A higher level of normative behavior in bilingual students shows the purposefulness and meaningfulness of their activities, the ability to self-organization and independence; also, a higher level of self-control among bilingual students shows stability in learning activities, in behavior, in decision-making, as well as discipline and control of their emotions in different situations. Responsibility and commitment, the ability to make decisions, dedication and perseverance of students lead them to success in their studies and in everyday life.

Thus, the results of the study in the second direction show the readiness of bilingual students to independently increase the level of intellectual development. A higher level for all factors, albeit in an implicit form compared to monolinguals, shows better indicators for the assimilation and comprehension of educational material, for self-organization and independence, for more developed intellectual and communicative abilities.

\section{Conclusions}

It is known that a nation is a real community with its own properties, that its interests and values have priority over other interests and values. A nation is a community of people with relatively stable characteristics of culture and language, as well as the consciousness of its unity and difference from others $[13,14]$.

Important elements of the spiritual and cultural life of the nation are culture, traditions, religion, literature, art, theater, stage, cinema, education system, mass media. In the event of the loss, "death", of the national language, all these aspects of the spiritual, cultural life of the nation are deprived of their origins, because national culture underlies all these aspects of social consciousness.

It can be assumed that the upbringing of children and youth in a foreign language does not allow them to build a more complete and harmonious picture of the world. Indeed, in the ethnic pedagogy of each nation, there are methods of upbringing, adaptation of the child to the world around, tested by many years of educational experience: first in the form of a protolanguage, games, toys, fairy tales, parables, jokes, elements of linguistic education, elements of national culture, etc. In the ethnopedagogy of the people, education is based on the age of the child. For each age, depending on the gender of the child and the manifested abilities and inclinations, upbringing is built in different ways, more individually. Gender education is also actively taking place, depending on the gender of the child. From here, cognitive and creative abilities are not fully revealed.

A young person's lack of knowledge of his native language leads to the fact that a person loses the whole world in the form of literary works, poetry, national vocal culture, and epics. Cultural codes that are well known to every representative of his nation become inaccessible to him. He remains outside the community of his nation, does not realize his unity with his people and his difference from other nationalities. In our study, it was revealed that children who do not speak their native language are distinguished by impressionability and superficiality.

It was also found that, in general, the level of development of cognitive processes in monolingual children is lower than in bilingual children who speak their native language. Bilingual children who speak 
their native language have higher indicators of the development of cognitive processes, which gives them an advantage over monolingual children, they have good adaptation to the world around them and to the educational process.

At an older age, differences are observed at all levels of personality manifestation. In general, a bilingual person has an advantage, a more pronounced competitiveness in self-realization, which in general can affect the severity of soft skills indicators (emotional intelligence, communication, problemsolving skills, decision-making skills, introspection, reflection, self-organization, independence, etc.).

\section{References}

1. D. Konyukhov Death of language in the postmodern era, Language and culture. Collection of articles of the XXIII International Scientific Conference, pp. 71-73 (Tomsk: TSU ed. house, 2013).

2. N.S. Galushin, Features of ethnic identity in the postmodern era, VII Congress of ethnographers and anthropologists of Russia: reports and speeches (Research Institute of Humanities. Sciences under the Government of the Republic of Mordovia. Saransk, 2007).

3. Analytical thinking and innovation, retrieved from: https://e-l-c.ru/top10skills.

4. A. L. Ricciardelli Bilingualism and cognitive development in relation to threshold theory Journal of Psycholinguists Research, 21 (4), 301-316 (1992)

5. D. K. Simonton Bilingualism and creativity $A n$ Introduction to Bilingualism: Principles and Processes p. 147-166 (Mahwah: Lawrence Erlbaum, 2008).

6. O. O. Adesope, T. Lavin, T. Thompson, C. Ungerleider A systematic review and metaanalysis of the cognitive correlates of bilingualism Review of Educational Research. 80(2), 207-245 (2010).

7. A. Pachev. Small sociolinguistic encyclopedia p. 17-18 (Pleven, 1993).

8. G.N. Volkov. Ethnopedagogy. (Moscow: Publishing Center "Academy", 1999)

9. R.S. Nemov. Psychology. Book 3. Psychodiagnostics. (Moscow, VLADOS, IMPE them. A.S. Griboedova, 2001).

10. 16PF Kettell Test Form A (187 questions), retrieved from: https: //onlinetestpad.com/ru/test/2-16pf-test-kettellaforma-a-187-voprosov.

11. K. Jung Tavistock Lectures. (MCNC and T "Centaur", 1994)

12. V.V. Znakov. Psychology of understanding the multidimensional world of man (Report) Bulletin of SPbU. 16 (1), (2016).

13. S.A. Vorobiev Ethnic identity in civil society: world experience and Russian perspectives, VII
Congress of ethnographers and anthropologists of Russia: reports and speeches (Saransk, 2007).

14. R.Z. Zakirov Formation of the ethnic and cultural identity of the Tatars in the twentieth century, Abstract for the degree of Doctor of Historical Sciences (2007) 